\title{
From Seia to Guimarães. Fernando Távora's tectonic shift in the Sacor fuel stations.
}

\author{
E. Fernandes \\ Landscape, Heritage and Territory Laboratory (LAB2PT), School of Architecture of the University of \\ Minho, Guimarães, Portugal
}

Between 1958 and 1961, the Portuguese architect Fernando Távora (1923-2005), designed two fuel stations in the north of Portugal for the same company, Sacor. These projects share the same client and a similar program, have the same type of location (on the outskirts of two medium-sized cities, Guimarães and Seia) and were designed by the same architect in subsequent periods of time (1958-60 and 1959-61).

There seems to be no reason that can justify any substantial differences in their design. Yet, although the granite stone was the dominant material in both constructions, they are different: the tectonic options of Távora were quite distinct.

This paper will present a tectonic analysis of these two fuel stations, considering Távora's 1960 journey to the USA as a key to explain this shift in his work.

\section{FERNANDO TÁVORA AND THE SACOR COMPANY.}

In the archives of Marques da Silva Foundation (where Fernando Távora's legacy is kept) we can find documented all the interactions between the Sacor fuel company and the architect; the key drawings to understand this collaboration are also published in the catalogue of the exhibition "Fernando Távora, Permanent Modernity" (Bandeirinha, 2012).

The first commission was a study for the location of Sacor petrol stations in the city of Porto and its environs; Távora's proposal was submitted in November 1957.

The project for the Sacor fuel station in Seia was the second commission, initiated in 1958, in Távora's studio, with the collaboration of Alberto Neves and Augusto Amaral; a preliminary proposal was designed in June 1958 and the final project was presented in December 1959; there are also some studies for additions designed between 1961 and 1965 (unbuilt).

In June 1959 Távora designed a prototype project to the petrol stations of the company, with the collaboration of Vasco Cunha. In the same date, he presented the first studies for the Gaia petrol station; this work continued until July 1960, when a second study was presented. In October 1961 , in a letter to the administration of Sacor, Távora assumes his incapacity to continue to develop this project (explaining that he is too busy with the process of application for associate teacher in the School of Fine Arts of Porto) and suggests that it should be transferred to another architect.

Finaly, in Abril 1959, Távora presents to Sacor the preliminary proposal for the petrol station of Guimarães (developed with the collaboration of Augusto Amaral), commissioned in the previous year; the final project was presented in May 1961, but there are some small adjustments designed in 1963 and 1965. A study for the reformulation and enlargement of the building, proposing a restaurant (presented in 1966, with the collaboration of Joaquim Sampaio), was not built. 


\section{CONTEXT.}

To recognize the importance of the shift in Távora's work for Sacor, we must understand his life journey until that moment.

He was born and raised within a noble and wealthy family, but his studies in the School of Fine Arts of Porto led him to a confrontation between his conservative education and the new world that his artistic sensibility was discovering, later summarized in the known statement "I joined the School enamored by the Venus de Milo and left fascinated by Picasso" (Ferrão, 1993, 23).

Távora's academic education was the result of the pedagogy of Carlos Ramos (Professor of Architecture since 1940, Director of the School from 1952 to 1969), who achieved a clear modernization of the teaching methods, surpassing some anachronistic features of the "Beaux-Arts" influence (Filgueiras, 1986). Yet, this modernization in the education of architects in Porto was in opposition to the evolution of Portuguese architecture in the forties, which was increasingly controlled by the nationalist policy imposed by Prime Minister António Salazar.

It was in this context that a 22-year-old Távora publishes his first text, "The Problem of the Portuguese House", in a weekly journal named Áleo, in 1945. This was a very courageous article, published under the dictatorship of Salazar and criticizing the official architectural doctrine of the fascist regime. In this text we can find the main ideas that will support his architecture, in the future: the will to learn from the past while thinking about the present and projecting the future; the purpose of combining the specificity of each site and cultural context with the lessons of modern architecture (Távora, 1945).

This text marks the beginning of a theoretical construct that Távora accomplishes in the next ten years, in a lonely and hard path, full of hesitations: between the mid-40s and the mid-50s, his texts presented a set of thoughts that he could not materialize in his buildings. He defended an idea of Modern Portuguese Architecture, claiming that it should be not only Portuguese, as the official doctrine of the fascist regime intended, or just Modern, as supported by the younger generations in the First National Congress of Architecture (held in Lisbon, in1948).

After the fragile attempts of his early projects, the signs of the genesis of a Modern Portuguese Architecture begin to appear in the municipal market of Vila da Feira (1954-59). This is the first work were we can recognize the full realization of the intentions expressed in his writings: its modernity is expressed in the "quality and accuracy of its relationships with life", in a "seamless integration of all its elements" (Távora, 1952a).

The market of Vila da Feira presents the seeds for the growth of an architectural identity that we can also find in other paradigmatic works of Távora that showed a new path to Portuguese Architecture: the private house in Ofír (1957-58), the tennis pavilion in Quinta da Conceição (Leça da Palmeira, 1956-59) and the Cedro Elementary School, in Gaia (1957-61).

The presence of Távora in the last CIAM meetings of Hoddesdon (1951), Aix-en-Provence (1953) and Dubrovnik (1956) must have contributed to the consolidation of his ideas, because he could understand that the will to relate the heritage of the modern movement with ancient cultural values was a common concern to other architects (mainly, some of the future members of Team $\mathrm{X})$. But the decisive factor for the establishment of this new path in Távora's work was the work process of the Surveys on Portuguese Vernacular Architecture; promoted by the Union of the Portuguese Architects between 1955 and 1960 (with the support of the government), these Surveys were conducted by Fernando Távora, Lixa Filgueiras, Keil do Amaral, Nuno Teotónio Pereira, Frederico George and Artur Pires Martins, who (heading six teams of three architects) were responsible for collecting and processing information from the six established zones. We can frame these Surveys in the context of the previous studies of the same kind already undertaken elsewhere; however, in Portugal, the enterprise encompassed a hidden agenda: despite the official support of the fascist regime, the intention of the promoters was to emphasize the hidden functionalist character of vernacular architecture.

These Surveys constituted a precious record of information about a reality that was already disappearing at the time. Therefore, caused by the echoes of the field work (since 1955) and by the publication of the resulting book, Arquitectura Popular em Portugal (Amaral, 1961), there was an emergent tendency in Portuguese architecture in the end of the fifties that became trendy in the early sixties: a regionalist style, in which traditional techniques and building materials (in conjunction with new materials and modern construction techniques), were used with the intent 
of seeking formal references in vernacular culture, even if the program or the context of the project should imply other options.

This was the context that framed the design of the Sacor fuel stations in Seia and Guimarães.

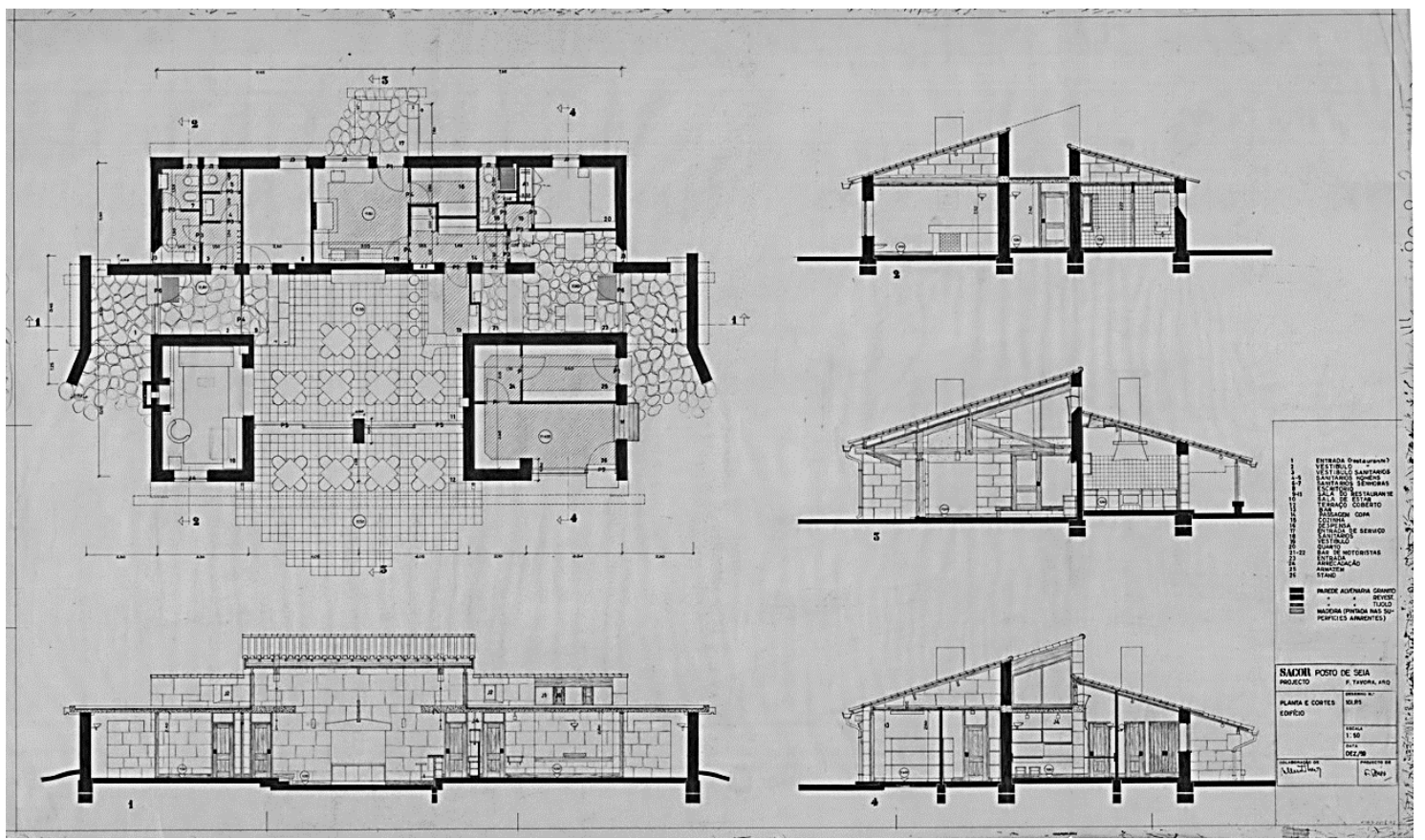

Figure 1. Final project for the Sacor fuel station in Seia, Fernando Távora, December 1959. Archives of Marques da Silva Foundation (FIMS_FT_0101-pd0018.02).

\section{SEIA.}

In Seia, like in most of the aforementioned work of Távora designed between 1955 and 1960, we find the use of traditional materials (stone, timber, tiles) and an attempt to reinterpret vernacular construction techniques (bearing walls, wooden beams and pitched tiled roofs).

This attitude is directly related to the results of the abovementioned Surveys and implies the recognition of a certain kind of 'modernity' in Vernacular Architecture.

The preliminary proposal presented to Sacor administration in June 1958 establishes the solution that will be presented in the final project (Fig. 1), with minor changes. The program was simple and common, with two distinct components: a fuel supply sector, where the pumps are located, and a building that houses the office of the station and a restaurant, with waiting room, dining hall, public bathrooms, kitchen, pantry, storage, a room for the night keeper, employee bathroom and a separate small dining room for the drivers.

When one travelled on the road between Seia and Covilhã, the petrol pumps appeared on the left, without any protection. They were separated from the platform of the restaurant, a little higher, by a small wall made of stone. The restaurant was located thirty meters away from the axis of the road, providing a terrace between the building and the fuel supply sector, where tables and chairs could be placed, if the weather was good; the building dominates "the site and the whole panorama, because it is located in a higher ground" and "takes the lead role of the composition" (Távora, 1960b, 3)

The building of the restaurant still presents today most of its features. It has a rectangular plan from which the two entries emerge, on both sides, standing out from the main volume; these entries are the only part of the construction that presents a flat roof, built in concrete, and a nonorthogonal direction: the bearing stone wall presents a torsion (Fig. 2) which reminds us of the entrance solution used by Távora in the Ofír house (similar to the organic solutions we find in vernacular construction).

Although the form and space were equivalent, the two entries served different purposes: the volume on the left was the public entrance for the general public and led to the central area of the 
restaurant, while the one on the right was the entry for the drivers, leading to a smaller dining room (Távora, 1961, 33). Today, because this separation does not make sense anymore, the entry on the right functions as a service access to the kitchen area.

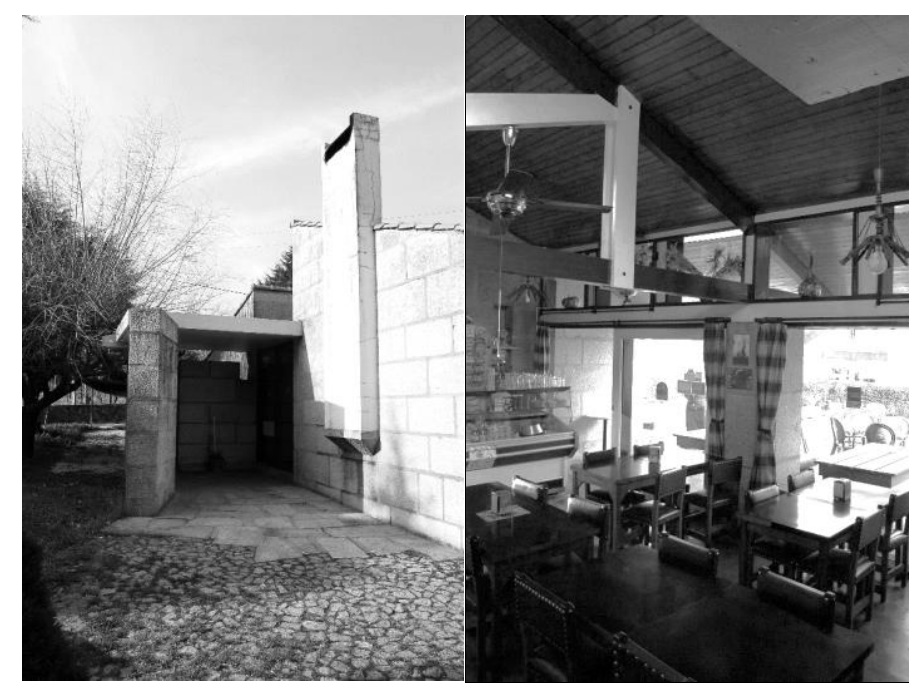

Figure 2. Távora's fuel station in Seia - left entrance and interior of the restaurant.

Photos by the author (2007).

In contrast with the simple, orthogonal and almost symmetrical plan, the sections show a complex articulation of spaces: from the narrow entrance, the flat roof is extended to the interior, conducting the visitor to a space that has a complex articulation. Parted by the extension of the concrete slab of the entries, the two slopes of the pitched roof begin clearly separated and only connect above the restaurant area, where the front one is extended to cover all the space of the room, creating a greater ceiling height. This central space is dominated by the presence of the central wood beam which supports the tiled roof, prolonged to the exterior terrace.

Like in his earlier work in Vila da Feira, Leça da Palmeira and Ofír, Távora achieves in Seia a perfect combination of local materials and traditional construction techniques (using stone bearing walls, timber beans and tiles) with modern ones (big glass windows and reinforced concrete slabs) which, together with the "spirit that presided to the design", should allow a "good integration in the environment" (Távora, 1960b, 3). However, if the source of these tectonic options can be found in Portuguese vernacular constructions, it also relates to some of Corbusier's work designed in the thirties, like the project for the Erazuris house, in Chile (1930) or the house in Mathes, La Rochelle (1935).

Besides, in Seia Távora achieves a "spatial conceptualization (...) underestimated in some of his earlier works", while "showing a truly exemplary modesty of appearance, in contrast to the advertising exhibitionism of other buildings of similar program we find in our roads" (Portas, 1961, 23).

\section{FROM SEIA TO GUIMARÃES.}

The preliminary proposal for Seia, presented in June 1958, is very similar to the final project, from December 1959. Likewise, Távora's first proposal for the petrol station of Guimarães (Abril 1959), presented great resemblance with the final project (September 1960). Studying these built proposals (and taking in account his unbuilt designs for the Gaia petrol station and the prototype projects for Sacor, on June 1959), we can identify a clear evolution in the concept associated with this program.

In Seia, the technical function of the petrol pumps should be performed by the Sacor employees, that would support the rain and the cold, without no shelter besides their winter uniforms (Fernandez, 2005, 341). This ancient idea of professional hierarchy, that justified the option of having no protection for the rain in the pumps area (later, a metallic cover was built, but it was 
not designed by Távora), was directly related to the principle of separation between the drivers and the general public, in the restaurant.

This was a direct response to the program presented by Sacor, which was to change, in the next commissions. In July 1958, the letter from the company administration that establishes the program for the prototype projects demands two solutions: one with a covered area for the pumps and another without any cover. In the written memory of his preliminary project, Távora claims that the proposed solution should "fit, as much as possible, the environment that surrounds it", repeating the principle already stated in the project for Seia, but adds that it "should, however, provide solutions perfectly contemporary in its form and in its construction" (Távora, 1959, 3).

Thus, in the petrol station of Guimarães (and also in the project for Gaia), we can notice the persistence of this transformation in the concept of the program, which is now directed for autoservice. In Távora's design, this modernization appears simultaneously with different tectonic options; although it is still possible to recognize the influence of the Vernacular Architecture of the north of the country, it is materialized in a different language: the bearing walls in granite stone are combined with flat roofs in reinforced concrete and metal pillars, as the concern for showing the possibilities of contemporary techniques overlaps the remaining references to traditional construction.

It is obvious that the program is different, also according to a distinct context. In Seia, it was destined to a touristic clientele, being on the outskirts of Serra da Estrela, the tallest mountain in Portugal. In an "international road" (Távora, 1961, 33), it should supply the needs of both people and vehicles, providing a restaurant. In Guimarães, it is meant to a different public, the urban owner of a private car. So, it presents a cover in the area of petrol supply. Besides the pumps, the commercial services of the petrol station and the public bathroom, which exist on both sides of the road (and are the main features of the program), the buildings on the West side should contain a bar and a covered esplanade open to the valley (in the road level) and (on the lower level) a house for the station employee (with living room, kitchen, two rooms and a bathroom), a mechanic workshop with washing facilities (for cars and trucks) and the staff locker room (Távora, 1961b, 2-3).

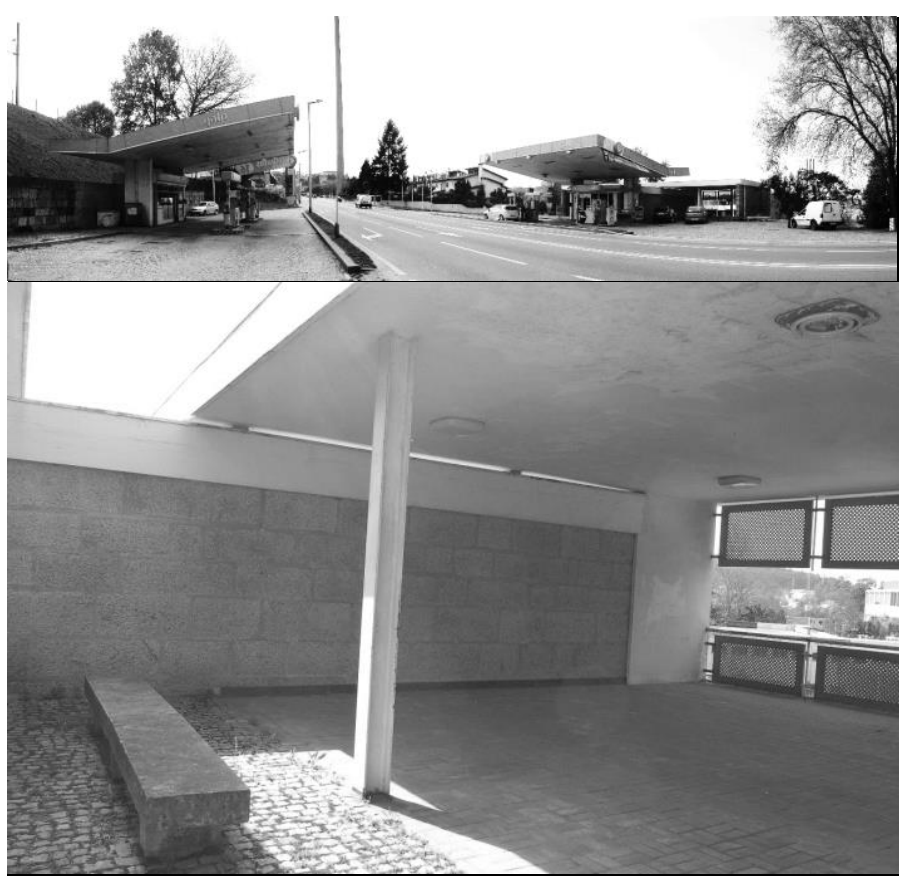

Figure 3. Távora's fuel station in Guimarães.

Photos by the author (2009).

Today, the building still presents an empty covered space in the upper floor, but it no longer functions as an esplanade, because the bar is no longer in use: its space is now occupied with a storage room and the access to the exterior was closed by concrete walls (which separates the 
south and north side of the esplanade, that were previously united); in the lower level, the house is unoccupied and the workshop is used as a warehouse.

Nevertheless, the construction still presents most of the original features. The relation to the road is not symmetrical; in the written memory of the final project Távora explains his options, according to the characteristics of the site: "it appears to us that the solution to be provided should rely on the existing slope to the West, with the protection and enhancement of the panoramic of the valley. The solution that is presented was essentially based on that initial impression, that later studies confirmed to be possible and profitable, and that justifies the establishment of a basement floor in the west position. As for the east position (...), it should perfectly balance the West position so that the assembly constituted a unity embracing the variant." (Távora, 1961b, 3).

It can be argued that, more than a petrol station, Távora was drawing a door for the city of Guimarães, with an imaginary arc suggested by the subtle movement of the two cantilever covers.

Although the set is not symmetrical, it is perfectly balanced, because the bigger area of the west side is withdrawn from the street and presents an empty volume, open to the view of the valley. Taking advantage of the topography, Távora locates most of program in the lower floor (below the street level), invisible at first sight but open to the landscape.

But it is mainly in the upper level that we can find the aforementioned different tectonics, especially in the structure system: the large and rectangular concrete slab covers the space and is supported, in the extremities, by two strong stone walls, while in the middle it is sustained by very delicate I-shaped steel columns.

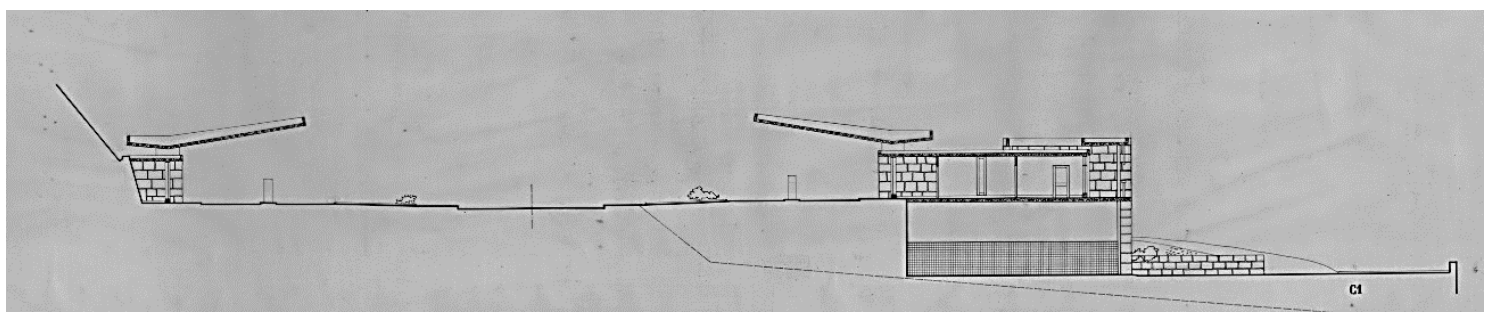

Figure 4. Section of the first project for the petrol station of Guimarães, Fernando Távora, January 1959. Archives of Marques da Silva Foundation (FIMS_FT_0106-pd0018).

This open box, parallel to the road, is intersected by a smaller closed volume, perpendicular to the street, which contains the office and the toilet facilities (and initially included the bar); its lateral walls are made of stone, which supported the rectangular concrete slab of its cover.

However, as the empty volume is a little taller than the closed one, they intersect as two completely different entities, and the slab of the bigger volume crosses over the slab of the smaller one, a few centimeters away. As it would not make any sense to superpose two independent concrete slabs, Távora interrupted the top one on the sector of the superposition. This is visible in the section shown on figure 4 , but difficult to understand on the site, because the concrete beam on top of the slab is continuous and hides the interruption, which is also concealed by the presence of the lower volume (fig. 3).

This is an abstract approach which is completely opposed to the complex articulation of spaces present in the Seia restaurant. In Guimarães, the interconnection between the different parts of the structure shows an influence of Mies van der Rohe that was never so obvious in the previous work of Távora and will not be repeated after this moment. It is the only building in his long career where we can sense a proximity to the elementarist approach of the German master, exemplary manifest in the pavilion design for the 1929 Barcelona International Exhibition.

\section{THE STUDY TRIP TO THE USA (1960).}

Since the end of the fifties, Portuguese architecture began to be dominated by the aforementioned regionalist style, related to the publication of Arquitectura Popular em Portugal (Amaral, 1961) and to the success of Távora's work in Vila da Feira, Ofír and Leça da Palmeira.

However, he believed that "Modern Architecture is not a style, but the result of an attitude" which "translates exactly, in a perfect relationship, the reality that surrounds it" (Távora, 1952a). This belief explains the tectonic shift in Távora's work for Sacor, which can be symbolized by 
the difference between the sloped roof of the preliminary designs of Seia and the flat roof in reinforced concrete in the preliminary project of Guimarães; on this process of change, it is curious to notice the early sketches for the Guimarães fuel pumps (from December 1958), where the section shows that the back volume was being considered with a sloped roof, which could prolong the movement of the cover of the pump area (fig. 5).

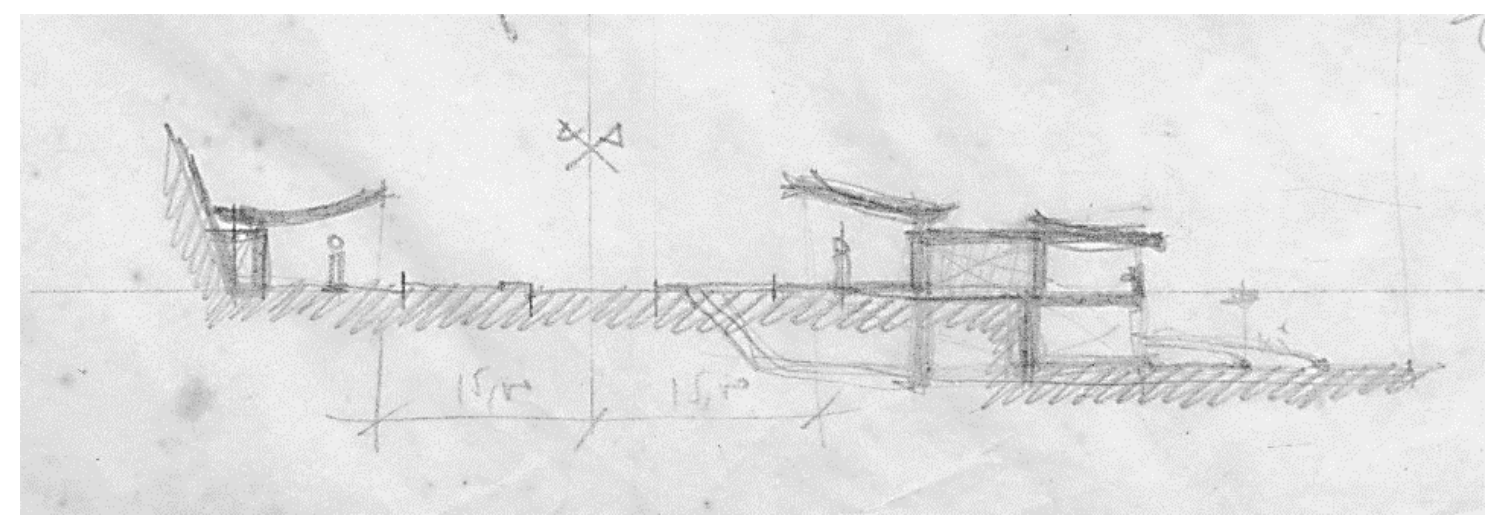

Figure 5. First sketches for the petrol station of Guimarães, Fernando Távora, December 1958. Archives of Marques da Silva Foundation (FIMS_FT_0106-pd0018).

So, in the end of this very creative period of time, Távora sensed that the formal influence of vernacular architecture symbolized an attempt to crystallize a reality that was, in fact, rapidly disappearing and could not translate the contemporary times. So, at this particular moment, he was seeking a different input to update his language, without losing the connection to the essence of Portuguese traditional values.

Távora's temporary proximity to the work of Mies van der Rohe in Guimarães can both be related to this necessity of a new direction in his field of research and the aforementioned conceptual evolution of the Sacor programs. The modernization of the program can justify the search for a language that can be related to the fascination for the machine that characterizes most of the production of modern architects in the twenties (and is beginning to be an important factor in Portuguese reality, at the end of the fifties). But this circumstance does not explain the choice of Mies; most of the work of Távora, since his 1948 design for the Urban Zone of Campo Alegre, in Porto, presented a fascination for the work of Corbusier, particularly evident in his 1950 unbuilt project for a House over the Sea (which was his final assessment for obtaining the architect diploma in the School of Fine Arts of Porto).

This sudden proximity to the German architect may have a different explanation.

In April 1959, Távora applied to a Scholarship Grant for the Calouste Gulbenkian Foundation, proposing a study trip to understand the methods of teaching Architecture and Urbanism in the United States of America. The scholarship was granted in January 1960 and the journey was completed between February and June 1960, mostly in American territory (but also in Mexico, Japan and Greece). Reading the diary (Távora, 1960a) that he wrote during this trip (recently published), it becomes obvious that this voyage must have been prepared several months before it started: Távora was following a predefined strict schedule that implied previous contacts with all the people he would meet in his various visits to the most important American Institutes and Universities. It is likely that it was being planned long before the appliance to the scholarship (which, probably, implied a detailed program).

It is also probable that, besides the preparation of this program, Távora dedicated some time studying the work of the architects of the buildings he would visit; reading his diary, it is obvious that there were two names which clearly interested him more, in the USA: Frank Lloyd Wright and Mies van der Rohe. So, the explanation for the shift in Távora's tectonic between the Sacor stations of Seia and Guimarães can be found in the combination of this recent interest in Mies' work with the aforementioned modernization of the conceptualization of the program.

But why was this moment of proximity to Mies' tectonics so ephemeral? Why is this work in Guimarães the only clearly miesien work of Távora? 
Reading the diary of his journey in America, we can find some clues for answering this question: his impressions on Mies work suffered a subtle evolution, between the unrestrained admiration for the Seagram building ("it is difficult to accomplish such quality with so much sobriety", p. 121) and the ambivalent feelings in the Chicago IIT: the Crown Hall is a work of "impeccable proportion and certainty (...) but has no mystery" and "can be very hot inside" (p. 245-7); the chapel is "scientific, rational and comfortable like most American churches" but presents "two identical façades, in the front and in the back", and Távora does not understand why Mies choses not to emphasize the front, the public access (p. 246).

This slightly disillusioned discourse contrasts vehemently with the enthusiasm he shows when visiting Frank Lloyd Wright's work, reaching the peak in his visit to Spring Green (p. 229-39) and in his lapidary conclusion: "after seeing Taliesin, Gropius' house seems like a refrigerator on the top of a hill"'.

\section{CONCLUSION.}

Tectonic options can be a powerful mechanism of expression in architecture, although the abstract, figurative or symbolic elements of architectural language may be favored by most investigators, which relegate tectonics to a mere question of construction techniques (Frampton, 1995, 20).

But, in most cases (like the ones analyzed in this text), tectonic options can be the key to explaining the architect's understanding of a particular site and the interpretation of a given program; mainly, it can express the particular circumstances of each work, evaluated by the architect, as an artist, as a technician and as a man of his time.

In Seia, we find the last remnants of the direct formal influence of vernacular architecture in the work of Távora; after all, the architects that worked in the Surveys knew, better than anyone else, that their work portrayed a reality that was rapidly disappearing.

So, in Guimarães, Távora experienced the expression of a modern society, designed for the private car, anticipating his trip to the USA (where this machine is a symbol of individual freedom); this was an unrepeatable moment, because the disappointment we can feel in his diary clearly discouraged him from repeating the experiment.

\section{REFERENCES.}

Amaral, K. (ed.). 1961. Arquitectura Popular em Portugal. Lisboa: Sindicato Nacional dos Arquitectos Portugueses.

Bandeirinha, J. A. (ed.). 2012. Fernando Távora, Permanent Modernity. Guimarães: G2012 / CEC / ACA / FFT / FIAJMS / FCG.

Ferrão, B. 1993. Tradição e modernidade na obra de Fernando Távora 1947/1987. In L. Trigueiros (ed.) Fernando Távora. Lisboa: Ed. Blau.

Filgueiras, O. L. 1986. A Escola do Porto (1940/69). In Fundação Calouste Gulbenkian (ed.) Carlos Ramos, exposição retrospectiva da sua obra. Lisboa: Fundação Calouste Gulbenkian.

Fernandez, S. 2005. Ristorante e stazione di rifornimento Sacor. In Esposito, A. \& Leoni, G. (eds.), Fernando Távora, opera completa: 340-1. Milano: Electa.

Frampton, K. 1995. Studies in Tectonic Culture. Cambridge, Massachussetts: MIT.

Portas, N. 1961. Fernando Távora: 12 anos de Actividade Profissional. Arquitectura 71: 11-23.

Távora, F. 1945. O Problema da Casa Portuguesa. ALÈO 5 (IV): 10.

Távora, F. 1952a. Arquitectura e Urbanismo - a lição das constantes. Lusíada 2 (1): 151-155.

Távora, F. 1952b. O Porto e a Arquitectura Moderna. Panorama 4 (I).

Távora, F. 1959. Memória descritiva e justificativa. Postos tipo de abastecimento para a Sacor. (Julho de 1959). Arquivo da Fundação Marques da Silva.

Távora, F. 1960a. Diário de "Bordo". Porto: Casa da Arquitectura, 2012.

Távora, F. 1960b. Memória descritiva e justificativa. Restaurante e posto de abastecimento Sacor em Seia. (Janeiro de 1960). Arquivo da Fundação Marques da Silva.

Távora, F. 1961a. "Restaurante e posto de abastecimento Sacor em Seia (1959-61)". Arquitectura 71: $32-$ 34.

Távora, F. 1961b. Memória descritiva e justificativa. Sacor. Posto duplo em Guimarães (20 Maio de 1961). Arquivo da Fundação Marques da Silva. 